\title{
DAS
}

\section{ARABISCHE MÄRCHEN}

\author{
VOM \\ DOCTOR UND GARKOCH. \\ HERAUSGEGEBEN, ÜBERSETZT UND IN SEINEM \\ LITTERARISCHEN ZUSAMMENHANGE BELEUCHTET
}

VON

\section{TH. NÖLDEKE.}

AUS DEN ABHANDLUNGeN DER KÖNIGL. PREUSS. AKADEMIE DER WISSENSCHAFTEN ZU BERLIN VOM JAHRE 1891.

\section{BERLIN 1891.}

VERLAG DER KÖNIGL. AKADEMIE DER WISSENSCHAFTEN.

IN COMMISSION BEI GEORG REIMER. 
Vorgelegt in der Sitzung phil.-hist. Classe am 30. April 1891

[Sitzungsberichte St. XXIII. S. 425].

Zum Druck eingereicht am gleichen Tage, ausgegeben am 30. Juni 1891. 
Ich will euch erzählen ein Märchen gar schnurrig.

Ich hoffe, durch diese Arbeit den Freunden harmloser, heitrer Volkslitteratur eine kleine Freude zu machen und zugleich einen nützlichen Beitrag zur Kunde von der Entstehung und Umformung des Märchens zu geben. Mein Verdienst ist dabei sehr gering. Das beste Material verdanke ich Zotenberg; er hat mich auch auf das türkische Avicennabuch aufmerksam gemacht. Goldziher hat mir das historische Urbild des Zauberdoctor's nachgewiesen. Damit war fast alles wesentliche gegeben. Herrn Dr. Hartmann bin ich für manche Belehrung über heutiges Arabisch verpflichtet; in anderer Weise haben sich Prof. Stern in Berlin, Dr. Geyer in Wien und Andere an dieser Schrift verdient gemacht. Die Verwaltung der Wiener Hofbibliothek hat mir gütigst zwei türkische Drucke geliehen, die der Gothaer Bibliothek in gewohnter Liberalität zwei Handschriften: ihnen allen meinen aufrichtigen Dank! 